\title{
CURSOS DE INGLÊS DO CELIN: OBJETIVOS, AVALIAÇÃO E TESTES DE NIVELAMENTO ${ }^{1}$
}

English Courses at Celin: objectives, evaluation and placement tests

\author{
Álvaro Antônio da LUZ, Celin-UFPR ${ }^{2}$ \\ Graziella Araújo de Oliveira LAPKOSKI, Celin-UFPR ${ }^{3}$ \\ Janice Inês NODARI, UFPR ${ }^{4}$ \\ Jeniffer Imaregna ALBUQUERQUE, UTFPR ${ }^{5}$ \\ Ronaldo CONTE, Celin-UFPR ${ }^{6}$
}

\begin{abstract}
RESUMO: A avaliação está presente em todo o processo de ensino e aprendizagem de uma língua. Avaliar o desempenho de alguém em uma língua estrangeira é uma responsabilidade para todos os sujeitos envolvidos no processo. Um grupo de estudos, formado por professores do Celin, propôs-se a trabalhar com os objetivos do curso como um todo e de cada nível, e com as avaliações do curso regular de Língua Inglesa do Centro de Línguas e Interculturalidade da UFPR, com o propósito de ler sobre avaliação e fazer sugestões bem informadas para guiar o processo de avaliação que acontece na instituição. Os critérios sugeridos pelos membros do grupo de estudos para avaliar os diferentes aspectos do desempenho dos alunos são apresentado em tabelas ao final do texto. A intenção é fazer uso desses critérios como diretrizes para a prática de avaliação.
\end{abstract}

PALAVRAS-CHAVE: Avaliação; Níveis; Critérios; Desempenho dos Aprendizes.

\footnotetext{
ABSTRACT: Evaluation is present in every teaching and learning process of a language. Evaluating someone's performance in a foreign language is a responsibility for all the subjects involved in the process. A study group, formed by teachers at Celin, aimed at working with the objectives of the English course as a whole, and with the objectives of each level at Celin - Center of Languages and Interculturality at UFPR Federal University of Paraná, with the purpose of reading on evaluation and proposing well-informed suggestions to guide the evaluation process which takes place at the institution. The criteria suggested by the members of the study group for evaluating

${ }^{1}$ Gostaríamos de agradecer à professora Lucianne Moreira por ter lido uma versão inicial deste texto e ter feito contribuições valiosas para o trabalho.

${ }^{2}$ Professor de Língua Inglesa no Celin - UFPR. Graduado em Letras pela UFPR.

${ }^{3}$ Professora de Língua Inglesa na UTFPR. Mestre em Letras pela UFPR.

${ }^{4}$ Professora de Língua Inglesa do DELEM, UFPR. Mestre em Letras - Inglês pela UFSC.

${ }^{5}$ Professora de Língua Inglesa na UTFPR, e assessora pedagógica no Celin - UFPR. Mestre em Letras pela UFPR.

${ }^{6}$ Professor de Língua Inglesa no Celin - UFPR. Graduado em Letras pela UFPR.
} 
different aspects of the students' performance are presented in tables at the end of this paper. The intention is to have the criteria as guidelines for the evaluation practice.

KEY WORDS: Evaluation; Levels; Criteria; Learners' Performance.

\section{INTRODUÇÃO}

A avaliação está presente em todo o processo de ensino e aprendizagem, em diferentes formatos e exercendo diferentes funções. Uma dessas funções apresenta-se quando do ingresso em um curso de língua estrangeira de um aprendiz que possui, ou não, algum conhecimento da língua alvo.

As avaliações são, entre outras coisas, instrumentos de poder nas mãos de quem as utiliza e, consequentemente, implicam em responsabilidade no que se refere à garantia de que elas refletem de forma precisa e confiável exatamente aquilo que se pretende avaliar. Este é um dos argumentos defendidos por McNamara (2000) ao ressaltar a seriedade e a responsabilidades exigidas do profissional que trabalha com avaliações e que precisa se envolver e ao mesmo tempo desenvolver seus conhecimentos a respeito do assunto. Diz ele que

há muitas razões para se desenvolver uma compreensão crítica dos princípios e práticas de avaliação de língua. [...] Primeiro, testes de língua representam um papel preponderante na vida de muitas pessoas, agindo como passaporte para importantes momentos de transição na escola, no trabalho, e em viagens internacionais. Como testes de língua são mecanismos para o controle institucional dos indivíduos, é evidentemente importante que eles devam ser entendidos, e que passem por um exame minucioso. Em segundo lugar, você pode estar trabalhando com testes de língua em sua vida profissional como um professor ou administrador do teste, preparando alguém para um teste, administrando testes, ou baseando-se em informações dos testes para tomar decisões sobre o nivelamento dos alunos para determinados cursos. Finalmente, se você está conduzindo uma pesquisa sobre o estudo da língua você pode precisar ter medidas da proficiência de língua dos seus sujeitos. (MCNAMARA 2000, p.4-5, tradução nossa).

\footnotetext{
${ }^{7}$ There are many reasons for developing a critical understanding of the principles and practices of language assessment. [...] First, language tests play a powerful role in many people's lives, acting as gateways at important transitional moments in education, in employment, and in moving from one country to another. Since language tests are devices for the institutional control of individuals, it is clearly important that they should be understood, and subjected to scrutiny. Secondly, you may be working with language tests in your professional life as a teacher or administrator, teaching to a test, administering tests, or relying on information from tests to make decisions on the placement of students on particular courses. Finally, if you are conducting research in language study you may need to have measures of the language proficiency of your subjects.
} 
Em outras palavras, podemos inferir que é cada vez mais imprescindível que professores estudem, desenvolvam, aprimorem seus conhecimentos sobre avaliação para poderem exercer a função de avaliador, inerente à profissão, com competência e eficiência.A consciência desta importância foi o ponto de partida para a formação do grupo de estudos "Cursos do Celin: Objetivos, Avaliação e Teste de Nivelamento". Através de um teste de nivelamento, aplicado no início de cada semestre no Celin, estabelece-se qual dos níveis ofertados é o mais adequado para o aluno naquele momento, em função dos conhecimentos que tem e do conhecimento esperado em cada um dos níveis do curso. Porém, para que se pudesse trabalhar com avaliação, era preciso ter muito claro o que avaliar: o "ponto de partida" e o "ponto de chegada" do curso, bem como cada uma das suas etapas. A partir disso, o grupo traçou seus objetivos.

O objetivo geral deste grupo de estudos foi possibilitar e ampliar a reflexão sobre a importância de estabelecer e seguir critérios de avaliação de aprendizes de Língua Inglesa que estudam no Celin - Centro de Línguas e Interculturalidade da UFPR, bem como daqueles que pretendem estudar ${ }^{8}$.

Como metas específicas, o grupo propõe-se a trabalhar com os objetivos do curso como um todo e de cada nível, com as avaliações e com os testes de nivelamento do curso regular de Língua Inglesa oferecidos na instituição, estabelecendo critérios que possam nortear as avaliações envolvendo os alunos do Celin. Ao mesmo tempo, tais orientações visam auxiliar os professores do Celin a tomar decisões bem informadas quando da avaliação de seus alunos.

A intenção foi de que este projeto se desenvolvesse em duas fases principais. Na primeira fase do projeto $^{9}$, propôs-se a elaboração de objetivos a serem atingidos pelos alunos ao final de cada nível, isto é, a elaboração de descritores de conhecimento, ou proficiência, na língua inglesa (ou L2). Pretende-se que estes objetivos (ou descritores) estejam de acordo com a proposta pedagógica de ensino e aprendizagem do Celin, qual seja a de unir o conhecimento produzido na Universidade com a prática

\footnotetext{
${ }^{8}$ Vale lembrar que o presente texto é produto dos resultados iniciais, apresentados oportunamente, e que, portanto, são os resultados parciais deste estudo, relativos ao $2^{\circ}$ semestre de 2011.

${ }^{9}$ As duas fases do projeto, embora distintas, não correspondem aos semestres letivos. A primeira fase, portanto, não foi ainda iniciada, mesmo que leituras sobre avaliação que venham a embasar o trabalho a respeito já tenham sido realizadas. Esta sobreposição de fases se deu pelo fato desses conhecimentos teóricos terem servido de base para um encaminhamento mais seguro dos objetivos propostos para a primeira fase.
} 
desenvolvida na sala de aula, de modo que o aluno seja convidado a participar de um processo de ensino e aprendizagem em que se valoriza o indivíduo enquanto ser ativo e capaz de construir sua identidade como falante da língua-alvo escolhida. Além disso, entende-se que os objetivos devem estar de acordo com o contexto sociocultural dos alunos, e sejam independentes de materiais didáticos adotados.

$\mathrm{Na}$ segunda fase, partindo dos objetivos previamente estabelecidos, propõe-se traçar parâmetros de avaliação, e estabelecer critérios gerais de avaliação e de correção de testes que, com as devidas adaptações pertinentes a cada nível de ensino, possam ser utilizados no curso todo. Concomitantemente, serão reformulados os testes de nivelamento de Língua Inglesa, com base em critérios de avaliação e de correção que sejam mais adequados aos objetivos anteriormente propostos. Esta segunda etapa seria desenvolvida na sequência, mas por questões de tempo, não o foi e não será, portanto, foco de atenção nesse texto.

Para que todos os objetivos propostos pelo grupo de estudos possam ser atingidos, fazem-se necessários, ao longo de todo o projeto, estudos teóricos que embasem e direcionem o trabalho como um todo. As leituras iniciais seguiram duas prioridades. A primeira, fazer o levantamento bibliográfico sobre avaliação, de maneira geral, para dar o suporte teórico necessário ao trabalho a ser realizado. A segunda, buscar quadros de referência internacionais em língua estrangeira que fornecessem um ponto de partida para o estabelecimento dos níveis de proficiência em cada um dos módulos do curso regular de inglês do Celin.

\section{FUNDAMENTAÇÃO TEÓRICA}

Para o embasamento dos níveis de proficiência, duas estruturas de referências utilizadas em avaliações internacionais foram analisadas: $C E F$ - Common European Framework e ACTFL - American Council on the Teaching of Foreign Languages; além de um quadro de referências, apresentado por Brown (2001) ${ }^{10}$. Para fornecer respaldo teórico ao estudo de avaliação, foram lidos alguns textos versando sobre avaliação em

\footnotetext{
${ }^{10}$ Ver referência completa na bibliografia e quadro proposto por Brown no anexo 4.
} 
língua estrangeira com o propósito de possibilitar a compreensão de alguns conceitos e definições fundamentais para o andamento dos estudos.

Dois desses conceitos são avaliação e teste:

Avaliação (Evaluation): "Avaliação pode ser definida como a coleta sistemática de informações para o propósito de tomada de decisões." ${ }^{11}$ (WEISS ${ }^{12}$, 1972, apud BACHMAN, 1991, p.22, tradução nossa).

Teste (Test): "um teste é um instrumento de medição elaborado para obter uma amostra do comportamento de um indivíduo. Como um tipo de medição, um teste necessariamente quantifica características de indivíduos de acordo com procedimentos explícitos."13 (BACHMAN, 1991, p.20, tradução nossa).

Uma das características da avaliação é que as informações obtidas não precisam ser, e não são todas, necessariamente, quantitativas. Em um curso de língua estrangeira, podem-se mencionar como exemplos a autoavaliação do desempenho do aluno; a avaliação do professor; a avaliação das instalações e dos recursos da escola; a avaliação da eficácia de uma atividade; entre inúmeras outras. Tais avaliações não podem ser classificadas como testes, e não se constituíram em objeto de estudo do grupo.

É necessário mencionar, no entanto, que o Celin adota, em sua proposta pedagógica, a perspectiva de língua das abordagens comunicativa e funcional, e tal perspectiva informa, portanto, os métodos avaliativos adotados. De acordo com Bynom (2001), testes embasados na abordagem comunicativa não só mensuram competência gramatical, sociolinguística e estratégica, mas também de que maneira essas competências podem ser utilizadas em situações de comunicação reais ${ }^{14}$. Uma vez que se adota a abordagem comunicativa no ensino de línguas estrangeiras, os testes precisam avaliar o aprendizado de acordo com essa mesma abordagem. Um teste comunicativo tem como "foco a expressão e o entendimento do uso funcional da

\footnotetext{
11 "Evaluation can be defined as the systematic gathering of information for the purpose of making decisions."

${ }^{12}$ WEISS, C. H. Evaluation Research: Methods for Assessing Program Effectiveness. Englewood Cliffs, NJ: Prentice-Hall, 1972.

13 "a test is a measurement instrument designed to elicit a specific sample of an individual's behavior. As one type of measurement, a test necessarily quantifies characteristics of individuals according to explicit procedures."

${ }^{14}$ Entendemos, aqui, por "reais" as situações de comunicação fora da sala de aula.
} 
linguagem, ao invés do domínio mais limitado da linguagem encontrado em testes sobre pontos discretos". (Bynom, 2001) ${ }^{15}$ Assim, pensando em termos avaliativos, não se mostra intrinsecamente necessário que a avaliação seja quantitativa, obtida exclusivamente através de pontos específicos, ditos discretos.

Uma grande vantagem da utilização do teste no ensino de línguas reside na sua capacidade de obtenção de tipos de comportamento possíveis de serem interpretados enquanto evidências da habilidade testada. Porém, para que possam ser úteis e refletir o conhecimento que se quer avaliar, os testes precisam seguir procedimentos preestabelecidos e ser preparados especialmente para o propósito utilizado. Para Brown, teste " é um método para medir a habilidade ou o conhecimento de uma pessoa em um determinado assunto. [...] É um conjunto de técnicas, procedimentos e itens que constituem um instrumento"16 (2001, p.384, tradução nossa).

Tal instrumento exige algum tipo de desempenho ou atividade por parte do aluno. E é este desempenho ou atividade que será testado.

Uma das questões principais é, então, assegurar que os testes avaliem o que se propõem avaliar da melhor forma possível; que seus resultados reflitam de forma precisa o conhecimento dos indivíduos avaliados. Isso, entre outras coisas, proporciona ao teste a qualidade esperada. Para tanto, há certos critérios de elaboração que visam garantir que os testes avaliem somente o domínio pretendido, diminuindo significativamente a interferência de fatores indesejados. Tais critérios incluem, por exemplo, desconsiderar a correção ortográfica em um teste de compreensão auditiva, buscando-se assim evitar que fatores externos, como a leniência ou o rigor de diferentes corretores, interfiram nos resultados e/ou na sua interpretação.

De acordo com Brown (2001), há três critérios clássicos por meio dos quais é possível avaliar a qualidade de um teste: a praticidade, a confiabilidade e a validade (sendo a literatura mais frequentemente consensual quanto à importância dos dois últimos). Estes critérios abrangem questões relativas não só ao processo de elaboração, como também à aplicação e à correção de testes. Um exemplo disso é a adequação dos

\footnotetext{
15 "Communicative tests are both direct and integrative. They attempt to focus on the expression and understanding of the functional use of language rather than on the more limited mastery of language form found in discreet point tests."

16 "is a method of measuring a person's ability or knowledge in a given domain. [...] It is a set of techniques, procedures, and items that constitute an instrument".
} 
testes elaborados quanto aos objetivos institucionais. No caso dos objetivos deste grupo de estudos, tal adequação implica em se ter a definição do nível de proficiência esperado para cada módulo de aprendizado, ao longo de todo o curso.

Ainda segundo Brown (2001), existe uma grande discussão entre professores de línguas com relação à divisão de proficiência de seus alunos em "iniciantes", "intermediários" e "avançados". Ainda que uma dada instituição queira se desprender dessas nomenclaturas, por entender que encerram os alunos em categorias que não são claramente definidas, permanece o fato de que os exames internacionais e os próprios alunos cobram uma divisão. Como comenta o autor

\begin{abstract}
Você irá notar na tabela de Speaking Guidelines (tabela 7, pp 100-101) que o termo "novato" substitui o termo "iniciante" devido à dificuldade de se estabelecer um ponto inicial definido na maioria dos aprendizes de línguas. Para a distinção do que numa conversa usual nós talvez chamaríamos de "iniciantes"

"falsos-iniciantes", o Guideline oferece o termo "novice low" e "novice mid" (Brown, p 98, 2001) $)^{17}$
\end{abstract}

A princípio, a observação de Brown (2001) pode parecer trivial, uma vez que cada instituição irá dar nome aos seus níveis distintos de proficiência. No entanto, a colocação do autor se mostra pertinente se considerarmos a discussão teórica que a precede. Considerando as implicações de adotar a abordagem comunicativa no ensino de língua inglesa e, por extensão, na aplicação de testes de proficiência, é possível concluir que, ao utilizar nomenclaturas como "novice-low" e "novice-mid", entende-se que aprendizado e avaliação se dão de forma gradativa, e não em etapas isoladas, ou estanques. Observando a estrutura longitudinal de um curso, do seu início ao seu fim, compreende-se a existência de níveis-chave, distintos dos outros por apresentarem uma imagem mais claramente identificável do progresso do aluno através do curso. Acrescente-se a essas considerações o fato de termos o inglês usado como língua franca e a inviabilidade de definirmos um falante nativo ou ideal como modelo. Estes foram outros pressupostos norteadores das discussões sobre avaliação e critérios.

\footnotetext{
17 "You will notice in the table of Speaking Guidelines (Table 7.1 on pp. 100-101) that the term 'novice' replaces the term 'beginning' due to the difficulty of establishing a definitive beginning point in most language learners. For the distinction between what in ordinary conversation we might call 'beginners' and 'false beginners', the Guidelines offer the terms 'novice-low' and 'novice-mid'."
} 
Tendo em vista o que foi discutido acima, demos início à análise preliminar dos níveis no Celin.

\section{IDENTIFICAÇÃO DOS NÍVEIS-CHAVE}

Na primeira reunião, o grupo de estudos estabeleceu como meta para o projeto a elaboração de descritores de níveis explicitando as habilidades que os alunos do curso de inglês precisam atingir ao final de cada módulo. O grupo entendeu ser necessário que tais descritores estivessem desvinculados do material didático utilizado no momento, de forma que os objetivos do curso pudessem ser estruturados independentemente de livros didáticos adotados ou não. Um dos objetivos do grupo é, justamente, possibilitar que o processo de análise e seleção de futuros materiais didáticos seja pautado nos objetivos propostos para o curso do Celin e não apenas no conteúdo dos livros analisados. Além disso, a existência dos descritores de níveis contribui para a clareza dos objetivos do curso, orientando o trabalho do professor em sala de aula e do avaliador em testes de nivelamento.

Para que os descritores de cada nível pudessem ser definidos, o grupo percebeu a importância de se estabelecer uma meta final para o curso e, a partir desta, pensar o restante dele como um contínuo visando àquele fim. Com base na experiência docente dos participantes do grupo de estudo e nos quadros de proficiência anteriormente citados, o grupo procurou identificar o que um aluno que conclui o décimo e último nível do curso do Celin é capaz de produzir na prática, em termos de uso da língua, e estabelecer qual é o conhecimento mínimo de língua que se espera que este aluno tenha adquirido ao final do último nível ofertado.

O primeiro passo para que os descritores dos níveis fossem definidos foi a elaboração de uma tabela de níveis de proficiência, adequada às necessidades do Celin, e que teve como ponto de partida as tabelas utilizadas pelo ACTFL, pelo Common European Framework e por Douglas Brown. ${ }^{18}$

\footnotetext{
18 Tabelas já mencionadas anteriormente e disponíveis nos sites relacionados nas referências bibliográficas.
} 
Em um primeiro momento, foi analisada uma tabela que apresentava critérios de avaliação geral, global, para a habilidade de speaking e para a habilidade de writing. Verificou-se que o nível final do curso do Celin, o décimo módulo ${ }^{19}$, pode ser caracterizado como nível B1 (falante independente em nível intermediário), mas com características de B2 (usuário independente) de acordo com os critérios apresentados pelos dois primeiros instrumentos de avaliação ${ }^{20}$. Porém, ao observar os critérios mais específicos apresentados por eles (ACTFL e Common European Framework), percebeu-se que os exemplos dados para as situações em que o aluno precisava desempenhar certas funções comunicativas restringia o escopo de atuação do professor quando apresentados pelo Common European Framework. Optou-se, então, por seguir os critérios propostos pela ACTFL, devidamente adaptados para a realidade do Celin, completando a tabela com os critérios para as habilidades de listening e reading.

Obtidos os descritores do final do curso do Celin ${ }^{21}$, o grupo buscou, então, identificar o que caracteriza o nível médio do curso, isto é, as habilidades que apresentaria um aluno tendo cursado metade da carga horária total do curso (5 módulos). Observando as habilidades de listening e reading do ACTFL, o grupo chegou à conclusão de que os alunos do Celin que terminam o nível 5 se encaixam em mais de uma categoria, podendo ser Novice-High, bem como Intermediate Low e que tal nível corresponde ao nível 1+ na tabela de Brown (2001) (vide anexo 4).

Em seguida, foi realizada a estruturação do nível 1 do curso, o nível de entrada, detalhado na próxima seção. Assim, obteve-se uma visão geral dos níveis-chave, "divisores de água" no processo de aprendizagem dos alunos do curso de inglês do Celin. A partir da estruturação destes três níveis, poderão ser estabelecidos os critérios a serem utilizados nos demais níveis.

Antes de apresentar o trabalho realizado em cada um dos três níveis, faz-se necessário explicar uma questão levantada ao longo do trabalho e o consenso a que o grupo chegou para definir os descritores de níveis. De partida, questionou-se se o perfil descrito em cada nível seria o do aluno com nota " 10 ", uma vez que este " 10 "

\footnotetext{
${ }^{19}$ Todas as informações em negrito são destaques propostos pelos autores desse texto.

${ }^{20}$ O nível 10 corresponde ao nível $2+$, de acordo com as observações feitas por H. Douglas Brown no capítulo 07 de seu livro "Teaching by principles".

${ }^{21}$ A tabela elaborada pelo grupo será chamada assim daqui em diante, para que não haja confusão entre esta tabela e os quadros de referência utilizados como base.
} 
significaria cem por cento de acerto em uma avaliação. Verificou-se que mesmo os quadros de referência para proficiência de uso internacional (ACTFL e Common European Framework), além de critérios para avaliação de prova de speaking como a do ECCE - Michigan Competency (para nível intermediário), dão espaço para o erro, considerando que o falante é passível de cometê-los - e não apenas por desconhecimento da estrutura da língua. Ficou decidido, então, que o "norte" do grupo na elaboração de critérios para cada nível seria o atingível, e não o ideal, uma vez que este não é facilmente mensurado. Foi decidido ainda que a produção equivalente à nota “7,0” seria o atingível, isto é, o que se espera que o aluno produza em cada nível para que ele esteja habilitado a cursar o nível seguinte.

\section{NÍVEL 1 - O QUE SE ESPERA}

Sendo o nível iniciante, o nível 1 não pressupõe que o aluno entre com conhecimento da língua. No entanto, ao final deste nível, o aluno que atinge nota 7,0 (sete) consegue mostrar que desenvolveu algumas competências relativas às quatro habilidades, detalhadas na sequência e apresentadas no anexo 1.

Em relação à produção oral os alunos terminam o nível com a habilidade de se comunicar minimamente com base em estruturas aprendidas. $\mathrm{O}$ aluno consegue interagir de forma simples, contanto que o interlocutor esteja preparado para repetir ou reformular informações em um grau de velocidade menor e ajude o aluno que está falando a formular as informações que ele quer transmitir. O uso de repertório básico composto de palavras isoladas e frases prontas está relacionado a detalhes pessoais e situações particulares concretas. O aluno pode interagir de forma bem simples, mas a comunicação é totalmente dependente de estratégias como repetição, reformulação e uso de ajustes.

Quanto à produção escrita o aluno de nível 1 tem condições de copiar ou transcrever palavras ou frases familiares e reproduzir algumas que foram previamente memorizadas. Ele também consegue preencher formulários com detalhes pessoais, mas em relação às estruturas gramaticais consegue demonstrar apenas um controle limitado de algumas formas em repertórios memorizados. Consegue ligar palavras ou grupos de palavras usando conectores básicos, tais como: "and" e "but". 
Já na compreensão oral, o aluno consegue finalizar o nível entendendo palavras isoladas, tais como termos cognatos, e palavras bastante frequentes em situações sociais. Além disso, consegue entender, por exemplo, algumas declarações curtas vistas previamente, especialmente quando o contexto dá suporte à compreensão e a fala é audível. O aluno compreende algumas estruturas de perguntas simples, de frases e de instruções usadas com frequência, além de fórmulas de cortesia sobre tópicos que se referem a informações pessoais básicas ou relativas ao seu contexto físico mais próximo.

Na compreensão escrita, o aluno tem condições de identificar palavras isoladas ou mesmo expressões quando estas são sustentadas pelo contexto. Ele também consegue identificar um número crescente de palavras e frases contextualizadas, incluindo termos cognatos e empréstimos quando apropriado. Além disso, o aluno nesse nível tem condições de entender as ideias principais e/ou alguns fatos de textos que abordam necessidades pessoais e sociais, tais como anúncios ou instruções. Exemplos incluem mensagens com propósitos sociais e informações para público mais variado. Tais textos são linguisticamente não complexos e tem uma estrutura interna clara, obedecendo uma sequência cronológica. Mesmo assim, alguns problemas de compreensão podem ocorrer.

Em linhas gerais, podemos dizer que as principais características do ensino e aprendizagem desse nível dizem respeito à repetição e ao uso da memorização. $O$ aprendizado que estamos aqui descrevendo parece ter uma forte ligação com os pressupostos dos modelos conexionistas. Para tais modelos, o aprendizado se dá através das conexões estabelecidas e da força entre elas nas redes neurais, da generalização de um padrão que se obtém pela observação do funcionamento de um número reduzido de dados/fatos.

Os mecanismos neurais são os responsáveis por gerar conhecimento não só linguístico, mas de outros processos que envolvem a interação humana. Ao contrário de pressuporem regras universais, como os inatistas, os conexionistas assumem que os aprendizes podem ter representações únicas a depender de uma série de fatores que estão associados, por exemplo, à língua materna (L1) do aluno, à natureza do input (ou insumo) recebido, dentre outros fatores. Em suma, os modelos conexionistas levam em conta fatores variados que atuam no processo de aquisição de linguagem, 
diferentemente dos modelos inatistas. No entanto, a literatura é controversa no que concerne a quais fatores considerar especificamente, por exemplo, como o aluno teve contato com a língua-alvo (L2 ou língua inglesa), como se deu o aprendizado, quais foram as condições em que o aluno adquiriu a língua, as diferentes metodologias de ensino pelas quais passou durante o aprendizado formal da língua, a idade em que a aquisição da L2 teve início, entre outros.

A partir do caráter associativo entre as informações linguísticas e os dados da experiência do indivíduo (como foram mencionados no parágrafo anterior), a mente humana procura criar ligações, formar elos que se tornam mais fortes a depender da recorrência com que as formas são apresentadas e recebidas pelo aluno. Com relação ao funcionamento do modelo, pode-se dizer que ele prevê um sistema de força de conexões no interior das redes neurais não estático, em que haveria "ajustamento da força da conexão", (RUMELHART et al., 1986). Nesse sentido, por exemplo, existem certos aspectos gramaticais da L2 que formariam conexões mais fortes com a L1, enquanto outros fariam conexões mais fracas. Assim, a repetição de estruturas poderia ajudar o aluno a criar uma forte conexão entre o conteúdo aprendido, de forma a poder utilizá-lo, novamente, em outro contexto.

A partir disso, entende-se que o objetivo geral desse nível é que o aluno consiga interagir, mesmo com dificuldades, em situações corriqueiras em que o interlocutor esteja preparado para ajudar. Além disso, a compreensão e o uso de expressões familiares do dia a dia e o uso de frases básicas têm o objetivo de satisfazer necessidades comuns. Mesmo assim, fica bem evidente que o aluno deste nível tem muito mais condições de identificar informações do que de produzi-las na língua-alvo.

\section{NÍVEL 5 - O MEIO DO CAMINHO}

O nível 5 do curso do Celin, conforme dito anteriormente, situa-se no "meio do caminho" do aprendizado, pois ao completá-lo, o aluno estará no quinto módulo (dois anos e meio se cursado em tempo regular), e terá ainda outros cinco até o término do curso. Em termos de produção, a análise das habilidades deste aluno traz um quadro interessante para pensar sua progressão com vistas ao que se estabeleceu como objetivo final para o nível 10. 
Da mesma forma que para os outros níveis, neste também propusemos um objetivo geral, e apresentamos descrições específicas para as quatro habilidades. Como objetivo geral, o aluno deste nível aprovado com média 7,0 (sete) deve ter condições de iniciar e manter interações por escrito e orais, um tanto previsíveis ainda, para satisfazer demandas sociais específicas. O uso da linguagem é um pouco menos limitado, mas a produção se restringe ao uso de termos simples para descrever situações pessoais, de seu ambiente e assuntos de seu interesse. Mesmo assim, percebe-se a evolução neste nível quando atentamos para a produção oral e escrita, especificamente.

Em relação à habilidade de produção oral o aluno de nível 5 do Celin tem condições de, por exemplo, estabelecer trocas comunicativas mesmo que para isso ele ainda faça uso de estruturas memorizadas. O que distingue o aluno desse nível do nível imediatamente anterior (nível 4) seria a espontaneidade na sua produção oral, mesmo que ainda sem muito suporte linguístico. $\mathrm{O}$ vocabulário deste aluno está centrado em temas que lhe são familiares, e a pronúncia ainda sofre interferência da língua materna (L1). Em outras palavras, o aluno comunica-se através de uma "interlíngua", termo cunhado pelo linguista Larry Selinker em reconhecimento ao fato de que os aprendizes de segunda língua (L2) constroem um sistema que lembra a primeira língua, ao mesmo tempo em que é diferente desta e da língua alvo sendo aprendida. A interlíngua de um aprendiz de língua estrangeira é, pois, um sistema linguístico único (ELLIS, 2001).

A fala do aluno de nível 5 é marcada por erros frequentes (mesmo ao utilizar estruturas já aprendidas), mas estes apresentam-se por vezes de forma produtiva, conforme explicado a seguir.

Os erros de produção passaram a ser vistos de maneiras distintas a depender do modelo teórico em voga. Ainda numa perspectiva behaviorista, o aluno que produzia algo considerado um "desvio" da forma padrão, realizava tal erro por não haver internalizado as regras para aquela determinada sequência. Com o passar do tempo, outros modelos emergiram, como a Análise Contrastiva, que levantou uma noção de "erro" distinta, propondo que o falante possui um papel ativo no processo de aprendizagem e que os erros cometidos não precisam receber reforço positivo (por exemplo, uma correção através da repetição da forma correta pelo professor). O erro é considerado parte do aprendizado e funciona como uma espécie de termômetro sobre o ponto no qual se encontra o desenvolvimento do aluno. O modelo que surge baseado 
nesse pressuposto inatista ficou conhecido como Modelo de Análise de Erros, tendo o trabalho de Corder (1967) como um dos trabalhos afiliados a esse modelo teórico.

Dois tipos de "desvios" são relatados por Corder (op cit): mistakes e errors. Embora não exista uma tradução para o português que diferencie essas duas palavras, a partir da descrição feita pelo autor, pode-se traduzir mistakes por "equívocos" - ou desvios casuais - e traduzir errors por "erros" - desvios que ocorrem de modo sistemático. Os equívocos acontecem devido a um lapso de memória, relacionado ao desempenho do falante, podendo ocorrer quando o falante está cansado ou sob algum tipo de pressão emocional. Os equívocos são, pois, assistemáticos, produzidos quando os falantes não aplicam apropriadamente as regras da língua. Assim, segundo Corder (op. cit.), tanto aprendizes de segunda língua quanto falantes nativos podem cometer equívocos. Por outro lado, os erros se dão pelo desconhecimento de algumas regras por parte do aluno, e, portanto, são relacionados a erros de competência.

Já em relação à habilidade de produção escrita o aluno desse nível faz uso das estruturas aprendidas, mesmo que por meio de cópias mecânicas, pois confia naquelas fórmulas já vistas. Isso equivale a dizer que muito pouco é produzido de forma realmente autônoma. Os tópicos explorados dizem respeito ao universo conhecido do aluno, e os textos produzidos são normalmente centrados no próprio aluno e em suas experiências. $\mathrm{O}$ aluno nesse nível pode, eventualmente, ir além e tentar produções mais ousadas, mas estas normalmente apresentam problemas na escolha lexical e na estrutura gramatical do que foi produzido. Outra característica marcante da produção escrita do aluno desse nível diz respeito à interferência da interlíngua, assim como acontece na produção oral.

No que concerne à habilidade de compreensão oral, esta normalmente não é linear e requer repetições e reformulações. Além disso, há dificuldades ocasionais de compreensão da ideia principal de um áudio, bem como de informação detalhada. No entanto, o aluno nesse nível apresenta condições de acompanhar e compreender textos ouvidos de maior duração, mesmo que estes sejam sobre tópicos diversos ou mesmo não familiares aos alunos. Embora os textos usados para compreensão auditiva nesse nível não sejam muito diferentes dos textos de níveis mais avançados, a compreensão pode ser dificultada pela presença de informações específicas complexas. $\mathrm{O}$ aluno- 
ouvinte identifica elementos de coesão no texto usado para compreensão auditiva, mas ainda não apresenta condições de seguir tais elementos para compreender o texto oral.

Em relação à habilidade de leitura e compreensão escrita, o aluno nesse nível tem condições de ler, de forma consistente e demonstrando grande compreensão, textos sobre uma variedade de necessidades básicas e sociais. Estes textos são linguisticamente não complexos e podem, ou não, apresentar uma estrutura interna bem delineada, como por exemplo, uma sequência cronológica. $\mathrm{O}$ aluno consegue inferir informações de descrições mais complexas, narrativas ou mesmo de reportagens e artigos curtos sobre temáticas contemporâneas e nos quais os autores adotem uma atitude ou ponto de vista peculiar, ou facilmente identificável. A complexidade estrutural de alguns textos interfere na compreensão, e relações estruturais e gramaticais simples, bem como referências temporais, podem estar simplesmente baseadas em itens lexicais e serem mal interpretadas. Mais detalhes relativos às habilidades e à produção esperada do aluno deste nível são detalhadas na tabela apresentada no anexo 2.

\section{NÍVEL 10 - O FINAL DO CURSO}

O nível 10, conforme apresentado anteriormente, foi o primeiro a ser descrito pelo grupo nas reuniões acordadas, partindo da necessidade de compreender o que se esperava em termos de competência linguística e comunicativa de um aluno que conclui as 600 horas de curso ofertadas pelo Celin. Ao considerar o nível 10 como nível final do curso, não se quer inferir que este seja o ponto final da aprendizagem do aluno, mas apenas que este é o último nível oferecido pelo Celin, daí a importância de bem definilo. Novamente, para melhor compreender a evolução do aprendizado, consideramos as quatro habilidades e suas peculiaridades descritas a seguir e detalhadas na tabela ao final do texto (vide anexo 3).

Em relação à habilidade de produção oral, o aluno é capaz de fazer perguntas utilizando uma variedade de estruturas, quando necessário, para obter informações que satisfaçam suas necessidades básicas (tais como: direções, preços, serviços, entre outras), ou complexas (ponto de vista, opiniões, entre outras). Ele também é capaz de criar com a língua, combinando elementos conhecidos e conversas para formular sentenças e mesmo discursos mais longos, tais como: breves seminários apresentando 
diferentes pontos de vista sobre um determinado tema, ou ainda relatos extensos de acontecimentos obedecendo a uma sequência lógica (contextualização, desenvolvimento dos fatos e definição) com uso satisfatório de elementos de conexão, sinalizando relações causais e temporais, dentre outras. A fala ainda pode conter pausas frequentes, reformulações e autocorreções. Inadequações em vocabulário, pronúncia e gramática podem causar problemas de compreensão, mas a produção oral é geralmente compreendida pelos interlocutores. O uso de falsos cognatos e traduções literais é ainda frequente.

Na produção escrita, o aluno pode lidar com confiança com a prática escrita de tópicos familiares, anotando palavras-chave e sentenças elaboradas com origem nestas. Consegue produzir textos de gêneros textuais variados sobre assuntos tais como: experiências de viagens, estudos, rotinas, preferências pessoais, narrando e descrevendo eventos de forma coerente. As referências de tempo são frequentemente inconsistentes, particularmente no uso de verbos compostos. $\mathrm{O}$ aluno também consegue escrever textos sobre tópicos relacionados a aspectos sociais, fornecendo argumentos e exemplos para dar suporte ao seu ponto de vista. O vocabulário usado é adequado em relação aos aspectos mais elementares e quando relacionado a tópicos familiares, mas pode ser inadequado para apresentar argumentações mais complexas e argumentos contrastantes. O estilo é normalmente informal, não apresenta bom comando de frases mais longas e complexas, e as expressões informais ainda podem ser usadas inadequadamente em textos que requerem linguagem mais sofisticada.

Em relação à compreensão oral, o aluno tem condições de compreender falantes nativos de diversas variedades da Língua Inglesa, especialmente em situações que envolvam a linguagem mais usual do dia a dia. Consegue ouvir informações específicas de forma efetiva em situações contextualizadas, focando em detalhes de descrições de eventos, lugares, sentimentos e vontades. O aluno tem condições de ouvir gravações mais longas, tais como palestras, e compreender as ideias principais. Ele também segue o desenvolvimento de narrativas, identificando suas principais etapas, tais como a introdução, o contexto, os principais eventos e o desfecho/resolução. Além disso, consegue seguir a sequência básica de discurso argumentativo, identificando a ideia principal e os detalhes de suporte. 
O aluno desse estágio final tem condições de seguir os eventos principais de séries de televisão e filmes envolvendo assuntos familiares, apesar de ter sua compreensão restrita pelo uso de vocabulário específico e das referências culturais que podem dificultar a compreensão total dos detalhes. Ele consegue identificar a atitude do falante e aspectos tais como dúvida, incerteza, ou ironia com base em vocabulário familiar, bem como em aspectos tais como entonação e marcadores de discurso pragmáticos. Consegue usar estes elementos para elaborar hipóteses sobre atos de discurso envolvendo a maioria dos itens lexicais complexos e não familiares.

Em relação à habilidade de compreensão escrita, o aluno nesse nível consegue ler de maneira crescente e consistente textos de complexidade mediana e algumas vezes avançada, adaptados ou não a partir de textos autênticos. Os textos podem apresentar desde uma temática mais básica e pessoal até assuntos contemporâneos e sociais. Frequentemente exigem do leitor a capacidade de fazer suposições mínimas e para as quais o leitor demonstra certo interesse pessoal e/ou conhecimento. Exemplos desses textos podem incluir artigos a respeito de problemas e práticas sociais, textos informativos e de opinião, charges, poemas, entre outros. Mesmo que os textos usados não sejam tão diferentes daqueles explorados em níveis mais avançados, a compreensão destes, neste nível, ainda é menos consistente, e o aluno nesse nível ainda pode precisar ler várias vezes um determinado texto para compreendê-lo.

De toda forma, o aluno desse nível tem condições de ler textos em prosa relativamente longos, principalmente se estes apresentarem uma estrutura interna clara. O leitor consegue extrair as ideias principais e os fatos apresentados, mas pode perder alguns detalhes. A compreensão deriva não apenas de conhecimento situacional e sobre o assunto, mas também de um maior domínio das estruturas da língua. Os textos nesse nível incluem descrições e narrativas compostas de contos, novos itens, informações bibliográficas, informativos sociais, correspondência pessoal, cartas comerciais de rotina, e materiais técnicos simples escritos para público não especializado.

Em linhas gerais, é possível verificar que o aluno, ao final desse nível, consegue satisfazer a maior parte dos requisitos relativos a trabalho lançando mão de linguagem que é, com frequência, mas não sempre, aceitável e efetiva. 


\section{CONSIDERAÇÕES FINAIS}

É preciso considerar que o curso de Língua Inglesa no Celin é completado em 10 níveis, mas que os níveis finais correspondem ao que normalmente se chama de nível intermediário de conhecimento da língua. Além disso, o grupo de estudos se propunha a apresentar critérios de avaliação que pudessem nortear a avaliação de todos os níveis, mas tal tarefa ainda não foi completada. Mesmo assim, o grupo envolvido com as discussões de nível apresentou neste texto o que considera algumas linhas gerais norteadoras para a avaliação dos níveis “divisores de águas”, quais sejam: nível 1, nível 5 e nível 10. Para delinear a proposta, o grupo considerou quatro aspectos, a saber: produção oral, produção

escrita, compreensão oral e compreensão escrita como elementos norteadores da proposta de desenvolvimento de critérios que embasassem as avaliações desenvolvidas no Celin.

Avaliou-se que o objetivo geral do grupo, que era o de possibilitar e ampliar a reflexão sobre a importância de se estabelecer e seguir critérios de avaliação do desempenho dos aprendizes de Língua Inglesa que estudam no Celin, foi atingido parcialmente, uma vez que ainda há níveis a serem contemplados em tal proposta e também porque não foi possível ainda propor diretrizes norteadoras para a aplicação de testes de nivelamento no Celin.

Os próximos passos do grupo de estudos dizem respeito a estabelecer discussões relativas às características dos aprendizes dos demais níveis ainda não contemplados nesse primeiro momento, bem como orientar os testes de nivelamento que acontecem no Celin e que atendem futuros aprendizes de língua inglesa interessados em ingressar na instituição. O grupo entende que a definição de diretrizes para avaliação do desempenho dos aprendizes de língua inglesa reflete uma postura engajada e preocupada por parte de seus integrantes para com o processo de aprendizagem da língua, e pode contribuir para o amadurecimento profissional dos professores do Celin no que diz respeito a refletir sobre sua prática como professores. 


\section{REFERÊNCIAS}

American Council on the Teaching of Foreign Languages. Disponível em: http://actflproficiencyguidelines2012.org/. Acessado em 01/07/2012.

BACHMAN, L. F. Fundamental Considerations in Language Testing. Oxford: Oxford University Press, 1991.

BROWN, H. D. "Learner variables II: teaching proficiency levels". IN: BROWN, H. Douglas. Teaching by Principles. An interactive approach to language pedagogy. $2^{\text {nd }}$ ed. San Francisco State University: Longman, 2001.

BYNOM, A. "Testing: Basic Concepts: Basic Terminology". IN: BYNOM, Anthony. English Teaching professional, Issue 20, July 2001.

Common European Framework of Reference for Languages. Disponível em: http://en.wikipedia.org/wiki/Common_European_Framework_of_Reference_for_Langu ages. Acessado em 0/07/2012.

CORDER, P. The Significance of Learners' Errors. IRAL, Heidelberg,v.5,n.4,p.161$170,1967$.

ELLIS, R. Second Language Acquisition. Oxford: OUP, 2001 [1997].

McNAMARA, T. Language Testing. Oxford: OUP, 2000.

RUMELHART, D. E., HINTON, G. E., and WILLIAMS, R. J. Learning internal representations by error propagation. IN: RUMELHART, D. E., McCLELLAD, J. L., and the PDP Research Group, (Ed.). Parallel Distributed Processing. Explorations in the Microstructure of Cognition. Volume 1: Foundations. The MIT Press, Cambridge, MA, p. 318-362, 1986. 


\section{ANEXO 1}

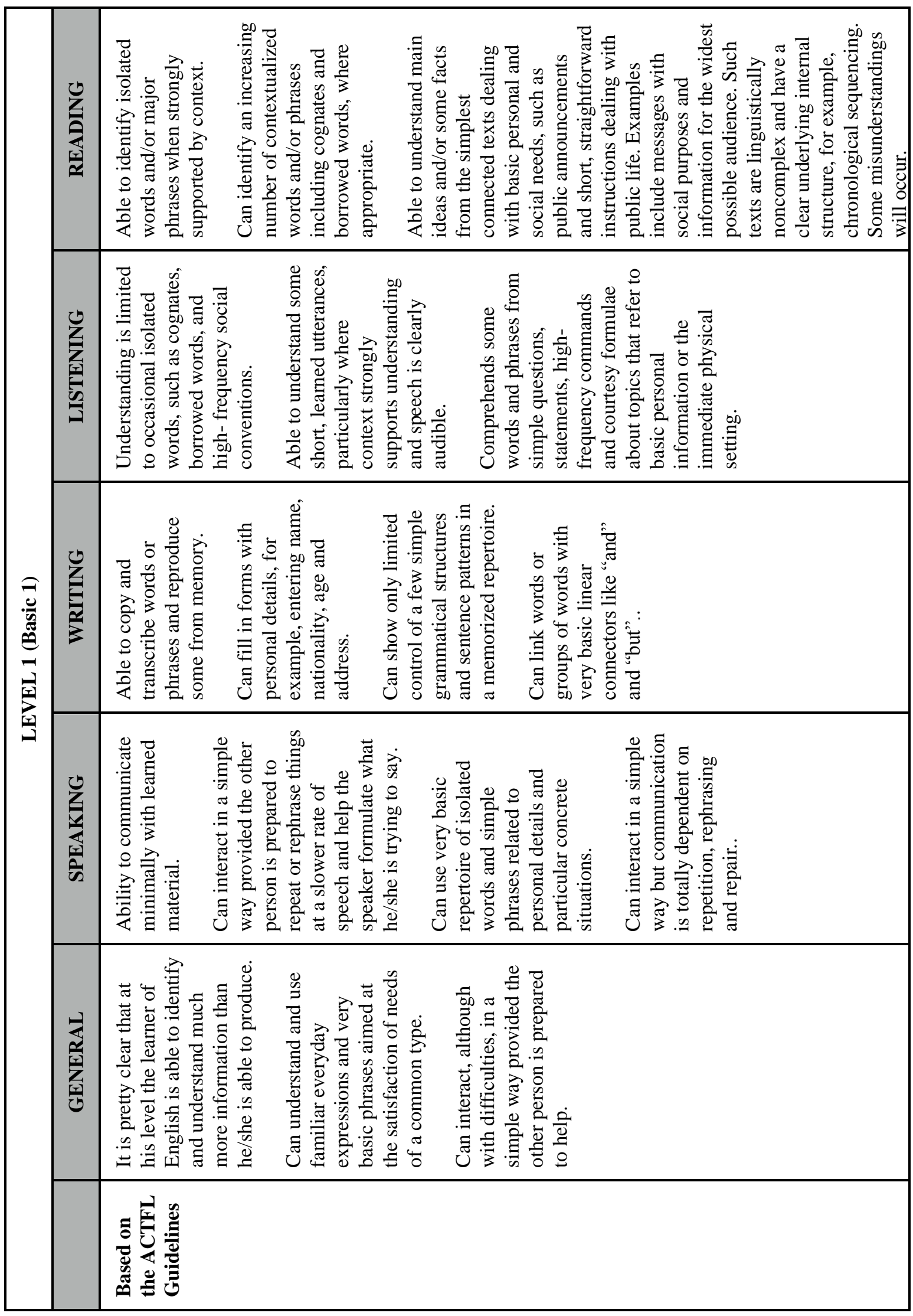




\section{ANEXO 2}

\begin{tabular}{|c|c|}
\hline 空 & 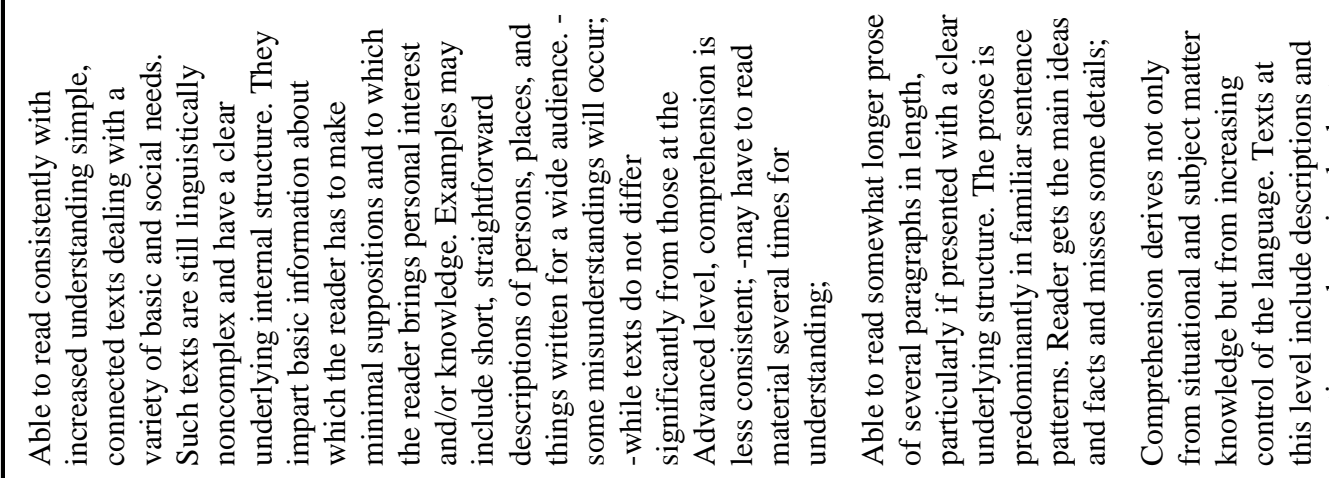 \\
\hline 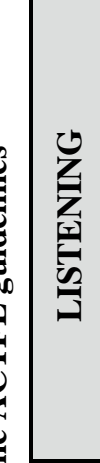 &  \\
\hline 党 &  \\
\hline$\frac{1}{2}$ &  \\
\hline 这 & 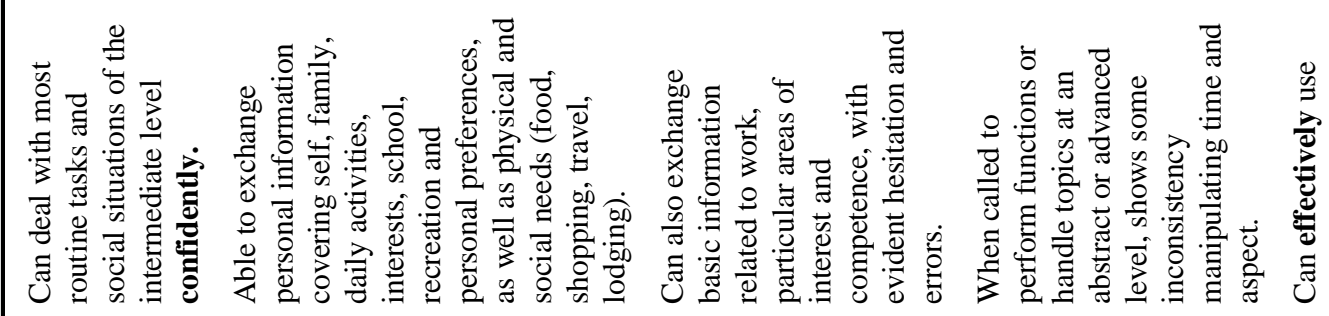 \\
\hline 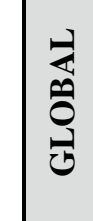 & 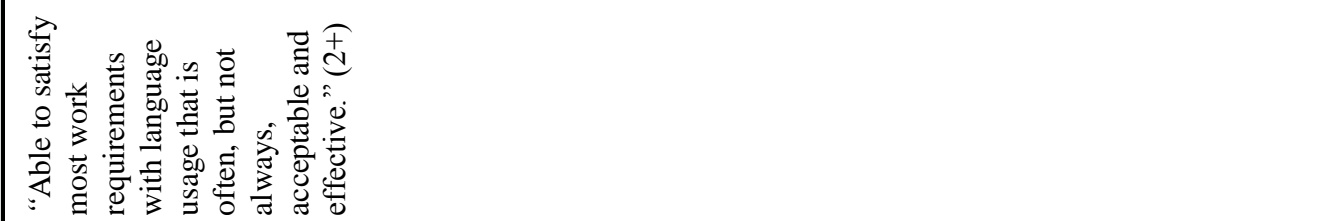 \\
\hline
\end{tabular}




\section{ANEXO 3}

\begin{tabular}{|c|c|c|}
\hline \multirow{6}{*}{  } & & 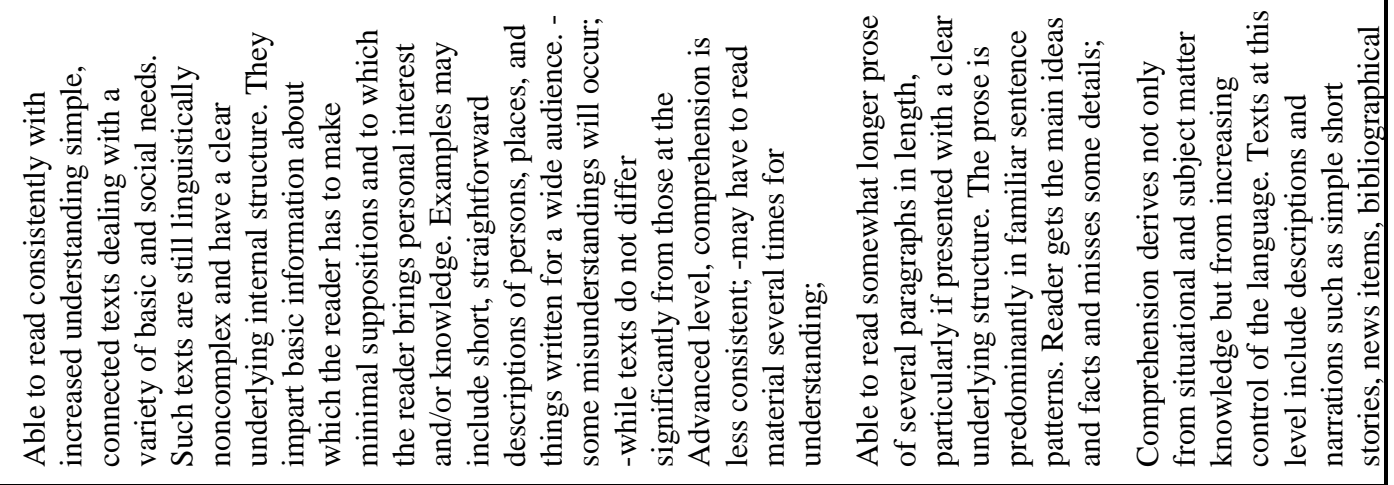 \\
\hline & 竞 & 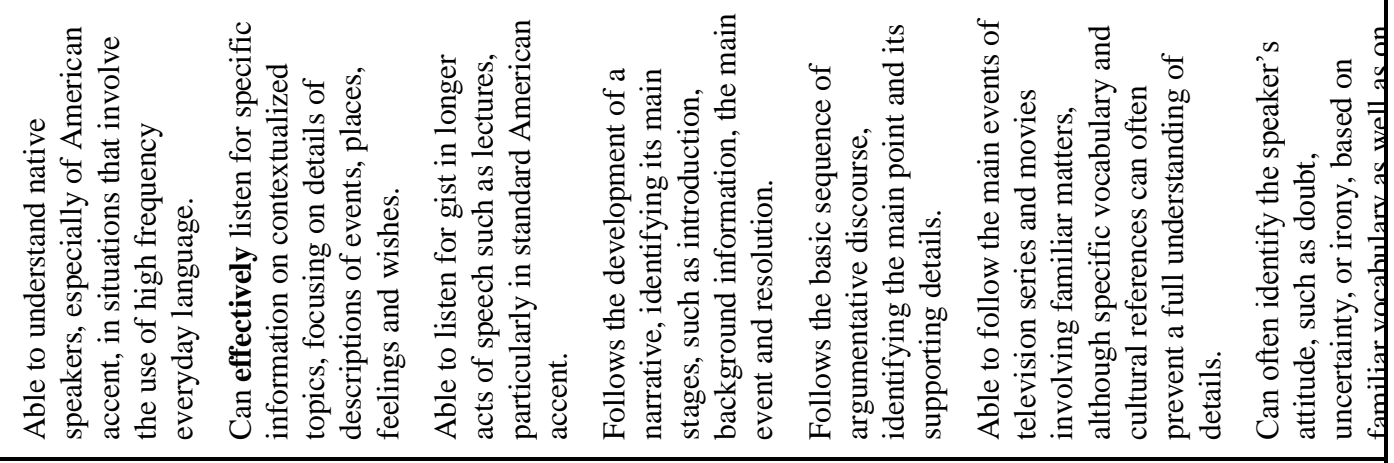 \\
\hline & 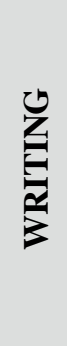 & 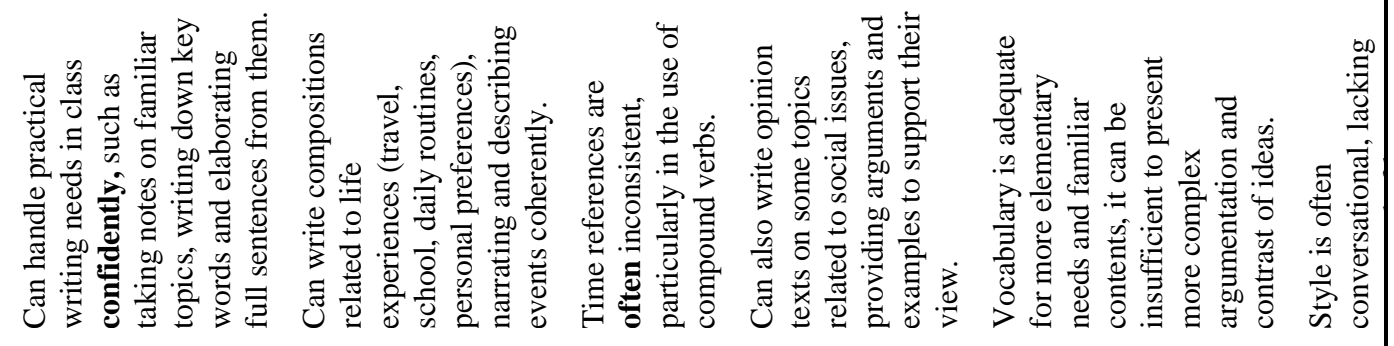 \\
\hline & $\frac{2}{2}$ & 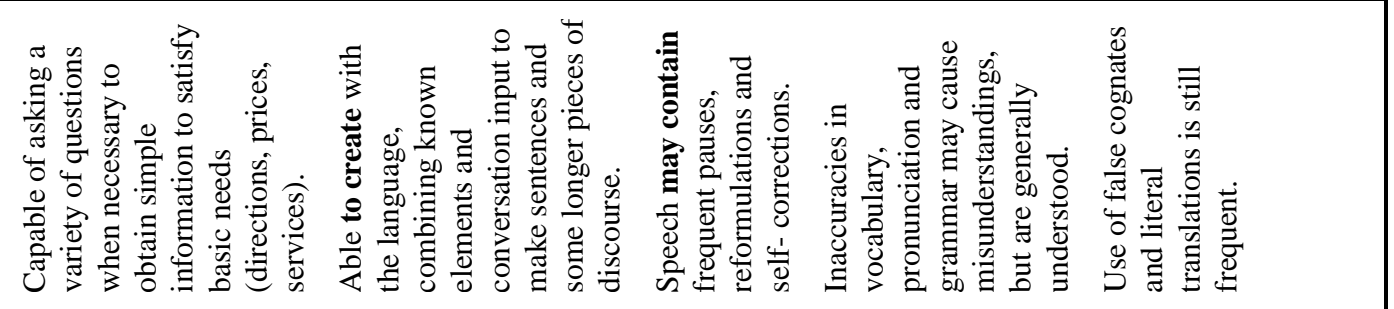 \\
\hline & 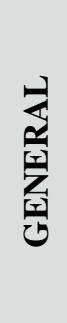 & 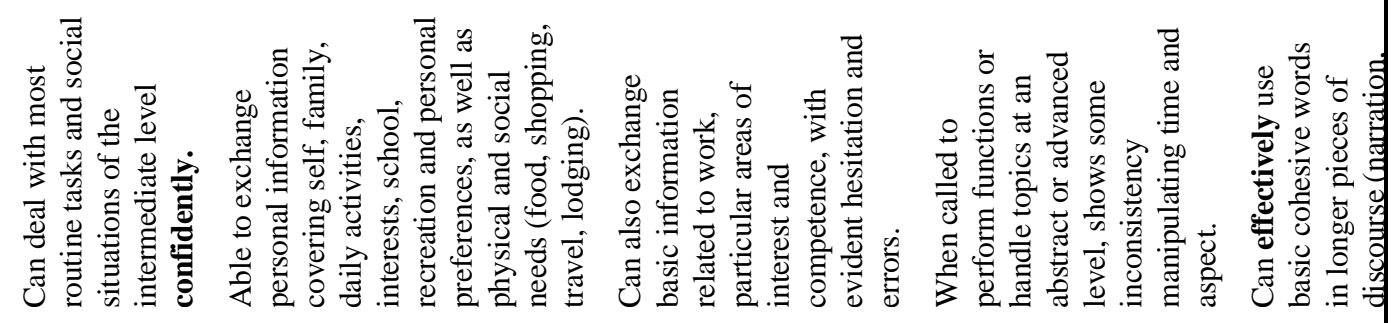 \\
\hline & 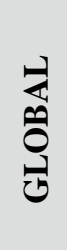 & 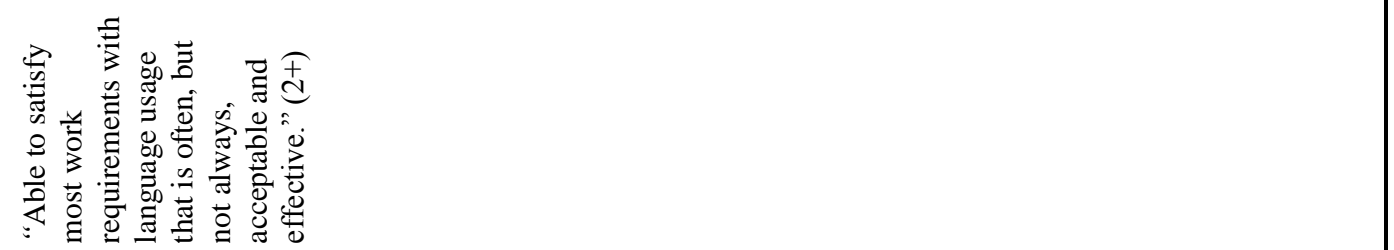 \\
\hline
\end{tabular}




\section{ANEXO 4}

Quadro de referências - Douglas H. Brown (2001, p. 97)

\section{LEVEL}

\section{DESCRIPTION}

$0 \quad$ Unable to function in the spoken language.

0+ Able to satisfy immediate needs using rehearsed utterances.

1 Able to satisfy minimum courtesy requirements and maintain very simple face-to-face conversations on familiar topics.

$1+\quad$ Able to initiate and maintain predictable face-to-face conversations and satisfy limited social demands.

2 Able to satisfy routine social demands and limited work requirements.

$2+\quad$ Able to satisfy most work requirements with language usage that is often, but not always, acceptable and effective.

3 Able to speak the language with sufficient structural accuracy and vocabulary to participate effectively in most formal and informal conversations on practical, social, and professional topics.

$3+\quad$ Often able to use the language to satisfy professional needs in a wide range of sophisticated and demanding tasks.

$4 \quad$ Able to use the language fluently and accurately on all levels normally pertinent to professional needs.

4+ Speaking proficiency is superior in all respects, usually equivalent to that of a well-educated, highly articulate native speaker.

5 Speaking proficiency is functionally equivalent to that of a highly articulate, well-educated native speaker and reflects the cultural standards of the country where the language is spoken. 